\title{
Role of Diatoms in the World of Forensic Science
}

\section{Kapil Verma*}

Amity Institute of Forensic Sciences (AIFS), Amity University, Noida-201303, Uttar Pradesh, India

\begin{abstract}
This article reviews the forensic aspects of Diatoms analysis and acid digestion method for diatoms extraction. A body recovered from the water does not necessarily imply that death was due to drowning. If the person is still alive when entering the water, diatoms will enter the lungs if the person inhales water and drowns. The diatoms are then carried to distant parts of the body such as the brain, kidneys, lungs and bone marrow by circulation. If the person is dead when entering the water, then there is no circulation and the transport of diatom cells to various organs is prevented because of a lack of circulation and diatoms cannot enter the body. When a body is recovered from water, there is usually a suspicion whether it was a case of ante-mortem or post-mortem drowning i.e. whether the body was drowned before or after death. In these medico legal cases, presence of diatoms in the body tissues is very useful evidence. In drowning related death cases, a correlation between the diatoms extracted from bone marrow and liver/lungs) samples and the samples obtained from drowning medium have to be established for the successful determination of drowning site in Forensic laboratories. Diatom analysis should be considered positive when number of diatoms is above a minimal established limit; 20 diatoms/ $100 \mu \mathrm{l}$ of pellet obtained from $10 \mathrm{gm}$ of lung samples and 50 diatoms from other organs and further matching of diatoms from bone marrow and drowning site can strengthen this supportive evidence and a positive conclusion can be drawn whether person was living or not when drowned. Detection of diatoms in the bone marrow is a proof that the individual was alive when entered the water.
\end{abstract}

Keywords: Diatom; Acid digestion methods; Organs; Lack of circulation; Drowning; Forensic laboratory

\section{Introduction}

Diatoms are photosynthesizing algae; they have a siliceous skeleton frustule and are found in almost every aquatic environment including fresh and marine waters, soils, in fact almost anywhere moist. They may be simple or branched, filamentous, and even enveloped in a gelatinous envelope or tube. All diatoms are enclosed by a frustule that is made up of two valves fitted together by a connective zone called a girdle. They are non-motile, or capable of only limited movement along a substrate by secretion of mucilaginous material along a slit-like groove or channel called a raphe (Table 1).

Diatoms are formally classified as belonging to the Division Chrysophyta; Class Bacillariophyceae Diatoms are divided into two Orders. The Centrales now called the Biddulphiales which have valve striae arranged basically in relation to a point, an annulus or a central areola and tend to appear radially symmetrical. The Pennales (Bacillariales), which have valve striae arranged in relation to a line and tend to appear bilaterally symmetrical; their silica-based skeletons do not readily decay and they can sometimes be detected even in heavily decomposed bodies. Diatoms do not occur naturally in the body. If laboratory tests show diatoms in the body that are of the same species found in the water where the body was recovered, then it may be good evidence of drowning as the cause of death.

Based on the study of drowning victims, where the diatoms are present in the medium, the penetration of diatoms into the alveolar system and blood stream has been caused by the breathing in of water by the drowning victims and then leads to the penetration of diatoms into other organs and parts of the body, such as bone marrow, the brain, kidneys and lungs [1,2]. Hard bones (sternum and femur) and soft tissues (lungs and liver etc) of drowned bodies are usually sent to the Forensic Science Laboratories for the detection of diatom. While solving drowning cases, a correlation between the diatoms extracted from these tissue samples and the samples obtained from putative drowning medium has to be established for the successful determination of drowning site. The occurrence of diatoms in the bone marrow is a proof that the individual was alive when entered the water. This means that the cause of death was due to the drowning.

More suggestions were given by [3] that diatom test would be of much importance in the diagnosis of drowning cases, origin of diatoms found in bone marrow is known i.e. matching of diatoms from both putative water medium and tissue of drowned body is must required for the success of this test. Some previous important reviews on diatoms and drowning have been published by Holden and Crosfill [4], Rushton [5], Timperman [6], Peabody [7]. Among the various works [8-15] have made good efforts to make this study live and hopeful one.

\section{Examination of Diatoms}

In 1942 Incze demonstrated that, during drowning, diatoms could enter the systemic circulation via the lungs. Their presence can be demonstrated in such tissues as liver, brain and bone marrow following acid digestion of the tissue. The use of diatoms as a diagnostic test for drowning is based upon the hypothesis that diatoms will not enter the systemic circulation and be deposited in such organs as the bone marrow unless the circulation is still functioning thus implying that the decedent was alive in the water. Before diatoms can be examined, they have to be cleaned. This involves the removal of cell contents, pigments, sand, mud or other material likely to interfere with microscope examination.

*Corresponding author: Kapil Verma, Amity Institute of Forensic Sciences (AIFS), Amity University, Noida-201303, Uttar Pradesh, India, Tel: +91-9717717119; E-mail: forensic.kapilalert@gmail.com

Received December 20, 2012; Accepted May 15, 2013; Published June 03, 2013

Citation: Verma K (2013) Role of Diatoms in the World of Forensic Science. $J$ Forensic Res 4: 181. doi:10.4172/2157-7145.1000181

Copyright: (c) 2013 Verma K. This is an open-access article distributed under the terms of the Creative Commons Attribution License, which permits unrestricted use, distribution, and reproduction in any medium, provided the original author and source are credited. 


\begin{tabular}{|l|l|}
\hline Cell size & Diatoms are commonly between $20-200$ microns in diameter or length, although sometimes they can be up to 2 millimeters long \\
\hline Cell wall & $\mathrm{SiO}_{2}$ or glass frustule \\
\hline Chloroplasts & Many/cell, 3-5 thylakoid membranes/stack \\
\hline Photo-pigments & Chlorophyll a \& c, carotenoids \\
\hline Reproduction: & Most often simple cell division, sexual reproduction \\
\hline Ecological roles & Produce deposits (diatomaceous earth), toxic blooms \\
\hline Common genera & Chaetoceros, Pseudonitzschia, Skeletonema \\
\hline
\end{tabular}

Table 1: Morphological characteristics of diatoms.

\section{Extraction methods}

Acid digestion method: The Acid digestion method for diatoms extraction accepted worldwide. It is easy to perform and gives good results; [2,11,16-44] are examples of workers who favoured this method for dissolving tissues samples.

\section{Nitric acid method:}

1. Samples are collected from the suspected drowning victim. Care should be taken as to not contaminate the sample with foreign diatoms during the process.

2. Intact femurs, for example, are removed at autopsy and washed in distilled water. Femurs are longitudinally sectioned using a clean band saw, and the bone marrow about $50 \mathrm{~g}$ is removed using a clean spatula and placed into a boiling flask.

3. Approximately $50 \mathrm{~mL}$ of concentrated nitric acid is added to the flask, and the marrow-acid suspension is boiled on a hot plate for approximately 48 hours-under a fume hood.

4. The suspension is then cooled and centrifuged, in some instances two separate times, with the supernatant discarded and the resulting acid-resistant material dropped onto clean microscope slides and the sediment is examined under the microscope.

A remarkable collection of most delicate and beautiful skeletons of diatoms is seen in cases of death from drowning. In favorable circumstances, even the site of drowning can be determined since the fresh water and the sea water diatoms are different and the sea water plants even vary from place to place along the coast.

\section{Sulphuric acid method:}

1. This has the advantage of not causing violent foaming. Check that all calcareous compounds have been removed first; otherwise the sample will become totally useless because gypsum crystals will form.

2. When sample has settled completely, discard supernatant.

3. Add concentrated sulphuric acid until the volume is twice that of the original sample.

4. Add potassium bichromate. In contrast to the $\mathrm{H}_{2} \mathrm{O}_{2}$ method, no special care is necessary as no violent reaction occurs. Just add enough bichromate to make for a saturated solution.

5. Let stand for 24 hours or more, or speed up the reaction in a water-bath 60 degrees. Even so, it may take several hours before the sample is clean. The sediment should look grayish and no plant fragments etc. should remain.

6. Let settle completely, discard supernatant and rinse several times as described above.

The sulphurics acid method seems to remove resistant "dirt" somewhat better than the $\mathrm{H}_{2} \mathrm{O}_{2}$ method, mainly because the oxidation reaction is not as abrupt as with peroxide. But again, the principal point is patience, not the chemistry involved.

Since diatoms resist putrefaction, the diatom test is particularly valuable, where decomposition is advanced. Diatom test is negative in dead bodies thrown in water and in dry drowning. In diatom examination invariably the control water samples must be used for comparison purpose. Standard diatom samples can be preserved on slides and can be used as standards for comparison purpose.

\section{Electron Microscopy}

In order to examine the morphology of diatoms, both transmission and scanning electron microscopes are able to provide a much more detailed image than light microscopes. These microscopes were necessary for taxonomical purposes, with the distinctions between species being so minute at times. Electron or dark phase microscopy is currently the main methods used for analysis. These allow for more detailed imaging than simple light microscopy $[45,46]$.

Transmission Electron Microscopy (TEM): This type of microscopy is best able to see the finer, delicate details of the diatom frustule (even if the frustule is not heavily silicified).

Scanning Electron Microscopy (SEM): SEM is best suited for visualizing the entire diatom frustule. It is a tool that can aid in viewing the gross morphology of a diatom (both internal and external parts).

The diatom test is considered positive when unequivocal diatoms are present on the slide. Incidences of positive diatom tests should be analyzed in relation to the season and month of drowning, if possible. As previously discussed, these factors can have an enormous effect on the number of diatoms discovered and the different genera represented. Discordances between diatoms found in the body and those in the putative drowning medium may suggest that either natural currents or human activity has moved the body, thus highlighting the importance of sampling the water source where the body is found [46]. By comparing the genera and species of diatoms found to regional samples, it may then be possible to localize the original site of a drowning in such cases [38].

The utility of the diatom test for drowning is directly linked to the incident of positive test results. With an occurrence of less than one third, the majority of drowning cases do not benefit from this method [45] have suggested three chief reasons for the low instances of positive test results.

The method of collection may not extract all the diatoms present in a sample and may miss diatoms altogether if only one or two individuals are present in the bone marrow--an issue that will be addressed later in a discussion of new methodologies increased test sensitivity.

Victims with heart conditions or other weaknesses of the circulatory or pulmonary systems who hyperventilate and pass out underwater or who experience a laryngeal spasm may die more quickly. This leads to 
a decreased volume of inhaled water and a lessened window of time where the circulatory system can embolize the diatom-containing medium $[3,45,47]$.

Finally, there is a relatively low volume of blood circulating to and through the bone and bone marrow [45]. This fact makes the investigation of other major dosed organs all the more important. Relying on negative test results based on the bone marrow alone may lead an investigator to miss what is actually a positive indicator of drowning.

Again, however, care must be taken to investigate only dosed organs. The suggestion given here is a balanced approach where care is taken to avoid contamination or insecure sources of diatoms, but where every possible secure diatom source is investigated and tested. Further, the authors contend that the development and testing of new modalities may increase the sensitivity and reliability of the diatom test.

Many workers, Peabody [48] Mueller and Gorgs [49]; Timperman [50]; Fukui et al. [51] etc. made many successful attempts for the isolation and detection of diatoms from the organs of drowned bodies. Water samples from the putative drowning site have also been taken under analysis for the presence of various diatom species more or less associated with drowning. Tyagi [33] and Ludes et al. [47] conducted a water monitoring system and generated a data base of diatom species from various water bodies like pond, lakes and canals for diagnosis of suspected drowning cases. They observe , P. braunii, Mastoglia smithioi, N. graciloides, , N. bacillum, N. radiosa, N. simplex, N. pusilla, Pinnularia mesolepta, P. gibba, Cymbella cistula, N. cryptocephara, Camera lucida, Navicula pupula, N. meniscus and many more species of diatoms in those water bodies. The content of diatoms in 5 samples; lungs, kidney, liver and femur marrow from each of four drowned and non-drowned persons were investigated by Foged [31]. Centric diatoms were frequently found and cosmopolitan Navicula and Synedra ulna was occurring in all cases. Auer [3] made qualitative diatom analysis recovered from the drowned body organs in Finland. In different body parts various types of diatom species i.e. Campylodiscus noricus, C. echenels; Epithelia zebra, Melosira nummuloides and Navicula pregrina; Pinnularia subcapitata; Achnanthes taeniata and Navicula ; Eunotia; E. lunaris , Meridian; Fragilaria crotonensi, Asterionella Formosa; Cymbella cymbiformis; Pinnularia borealis; Pinnularia capsoleta, Tetracyclus lacustris and Cymbella were observed. During continuous river monitoring Ludes et al. [47] analyzed both water and tissue for the presence of diatoms and Navicula, Diatoma, Nitzschia, Stephanodicus, Fragilaria, Gomphonema, Gyrosigma, Melosira, Achnanthes, Amphora, Cocconeis, Cyclotella was commonly found diatoms.

\section{Discussion}

The main goal in this field is to differentiate a death by submersion from an immersion of a body. Laboratory tests may reveal the presence of diatoms in the body. Diatoms are microscopic algae found in both seawater and fresh water. Their silica-based skeletons do not readily decay and they can sometimes be detected even in heavily decomposed bodies.

If the person is dead when entering the water, then there is no circulation and the transport of diatom cells to various organs is prevented because of a lack of circulation and diatoms cannot enter the body. When a body is recovered from water, there is usually a suspicion whether it was a case of ante-mortem or post-mortem drowning i.e. whether the body was drowned before or after death. In these medico legal cases, presence of diatoms in the body tissues is very useful evidence. In drowning related death cases, a correlation between the diatoms extracted from bone marrow and liver/lungs) samples and the samples obtained from drowning medium have to be established for the successful determination of drowning site in Forensic laboratories

However, it is important to remember that the absence of diatoms does not immediately rule out drowning; the test does not prove the negative, and a thorough investigation is always required. Again, if specific types of diatoms recovered from the marrow can be matched with those found at the suspected drowning site, the results might implicate a particular locale of submersion and help identify the death scene, which in turn could lead to additional forensic evidence. The presence of diatoms can also corroborate investigative evidence in making accident determinations $[37,45]$.

Diatom analysis can be of further use in forensic science through identifying the provenance of individuals, clothing or materials from sites of investigation [2,7,45,52-54]. Where materials have been submerged or there has been contact with littoral or riparian sediment or vegetation, diatom analysis of sediments or other diatomaceous traces present on clothing or footwear can be used to identify the type of habitat [54]. One or more water samples from the site of drowning should be taken. If there is any doubt about the drowning site, then water sample from the putative site of drowning can be collected and analyzed to determine the similarity of different species of diatoms in the water and the body.

\section{Conclusion}

Diatom analysis should be considered positive when number of diatoms is above a minimal established limit; 20 diatoms/ 100 $\mu \mathrm{l}$ of pellet (obtained from $10 \mathrm{gm}$ of lung samples) and 50 diatoms from other organs [47] and further matching of diatoms from bone marrow and drowning site can strengthen this supportive evidence and a positive conclusion can be drawn whether person was living or not when drowned. The diatom test, while extremely specific, is of immense value considering the limited objective tests available for drowning diagnoses. A fresh outlook is necessary to rekindle use of this important application to medico legal investigations. It has been suggested that marrow of the sternum may be as good of a source of diatoms as femoral tissue. Death of a victim found in water should not always be related to drowning.

If the person is still alive when entering the water, diatoms will enter the lungs if the person inhales water and drowns. The diatoms are then carried to distant parts of the body such as the brain, kidneys, and bone marrow by circulation. If the person is dead when entering the water, then there is no circulation and diatoms cannot enter the body. Diatoms do not occur naturally in the body. If laboratory tests show diatoms in the corpse that are of the same species found in the water where the body was recovered, then it may be good evidence of drowning as the cause of death. Bone marrow is described as a sanctuary organ and if diatoms reach this tissue, the diagnostic of drowning could be assessed.

\section{References}

1. Rohn EJ, Frade PD (2006) The Role of Diatoms in Medico legal Investigations: The History, Contemporary Science, and Application of the Diatom Test for Drowning, The Forensic Examiner Fall.

2. Krstic S, Duma A, Janevska B, Levkov Z, Nikolova K, et al. (2002) Diatoms in forensic expertise of drowning--a Macedonian experience. Forensic Sci Int 127: 198-203. 
3. Auer A (1991) Qualitative diatom analysis as a tool to diagnose drowning. Am J Forensic Med Pathol 12: 213-218.

4. Holden HS, Crosfill JWL (1955) The significance of foreign bodies in the alveoli of the apparently drowned. J For. Med 2: 141-50.

5. RUSHTON DG (1961) Drowning--a review. Med Leg J 29: 90-97.

6. Timperman J (1979) personal communication

7. Peabody AJ (1980) Diatoms and drowning--a review. Med Sci Law 20: 254261.

8. Pollanen MS (1996) The diatom test for drowning in Ontario. Canadian Society of Forensic Science 29: 205-211.

9. Ludes B, Quantin S, Coste M, Mangin P (1994) Application of a simple enzymatic digestion method for diatom detection in the diagnosis of drowning in putrified corpses by diatom analysis. Int J Legal Med 107: 37-41.

10. Rohn EJ, Frade PD (2006) The role of diatoms in medico legal investigations I: The history contemporary science and application of the diatom test for drowning. Forensic Examiner: 10-15.

11. Pachar JV, Cameron JM (1992) Scanning electron microscopy: application in the identification of diatoms in cases of drowning. J Forensic Sci 37: 860-866.

12. Gruspier KL, Pollanen MS (2000) Limbs found in water: investigation using anthropological analysis and the diatom test. Forensic Sci Int 112: 1-9.

13. Hürlimann J, Feer P, Elber F, Niederberger K, Dirnhofer R, et al. (2000) Diatom detection in the diagnosis of death by drowning. Int J Legal Med 114: 6-14.

14. Natasha D, Aleksej D (2005) Differential diagnostic elements in the determination of drowning. Rom J Leg Med 13: 22 -30.

15. Horton BP, Boreham S, Hillier C (2006) The development and application of a diatom-based quantitative reconstruction technique in forensic science. J Forensic Sci 51: 643-650.

16. MUELLER B (1952) [The problem of diagnosis in death by drowning]. Dtsch Z Gesamte Gerichtl Med 41: 400-404

17. Tomonaga T (1954) The diagnosis of drowning by wet digestion. Jpn. J. Legal Med 8: 143-149.

18. THOMAS F, VAN HECKE W, TIMPERMAN J (1961) The detection of diatoms in the bone marrow as evidence of death by drowing. J Forensic Med 8: 142144

19. Bhaskar GR (1965) Diatoms in Cases of Drowning. JIA FS 4: 3-5.

20. Calder IM (1984) An evaluation of the diatom test in deaths of professional divers. Med Sci Law 24: 41-46.

21. SPITZ WU, SCHNEIDER V (1964) THE SIGNIFICANCE OF DIATOMS IN THE DIAGNOSIS OF DEATH BY DROWNING. J Forensic Sci 9: 11-18.

22. Porawski $R$ (1966) Investigations on the occurrence of diatoms in organs in death from various causes. J Forensic Med 13: 134-137.

23. Neidhart DA, Greendyke RM (1967) The significance of diatom demonstration in the diagnosis of death by drowning. Am J Clin Pathol 48: 377-382.

24. Koseki T (1968) Fundamental examination of experimental materials and control animals on the diagnosis of death from drowning by the diatom method. Acta Med Boil 15: 207-219.

25. Hendey $\mathrm{NI}$ (1973) The diagnostic value of diatoms in cases of drowning. Med Sci Law 13: 23-34.

26. Nanikawa R, Kotoku S (1974) Medicolegal observations on a dead body drawn up from the sea bed, with special reference to ethanol and diatoms. Forensic Sci 3: 225-232.

27. Khattab M (1975) Diagnosis of death by drowning; a quick method for detection of diatoms in bone marrow and different organs. J Egypt Med Assoc 58: 537546 .

28. Udermann H, Schuhmann G (1975) [An improved method for detection of diatoms (author's transl)]. Z Rechtsmed 76: 119-122.

29. Peabody AJ (1978) Diatoms in forensic science. J Forensic Sci Soc 17: 81-87.

30. Schellmann B, Sperl W (1979) [Detection of diatoms in bone marrow (femur) of nondrowned (author's transI)]. Z Rechtsmed 83: 319-324.
31. Foged N (1983) Diatoms and drowning--once more. Forensic Sci Int 21: 153 159

32. Calder IM (1984) An evaluation of the diatom test in deaths of professional divers. Med Sci Law 24: 41-46.

33. Tyagi GD (1985) Diatoms of Delhi. Journal of Forensic Medicine and Toxicology 2: $18-23$.

34. Auer A, Möttönen M (1988) Diatoms and drowning. Z Rechtsmed 101: 87-98.

35. Pachar JV, Cameron JM (1993) The diagnosis of drowning by quantitative and qualitative diatom analysis. Med Sci Law 33: 291-299.

36. Taylor JJ (1994) Diatoms and drowning--a cautionary case note. Med Sci Law 34: 78-79.

37. Pollanen MS (1997) The diagnostic value of the diatom test for drowning, II. Validity: analysis of diatoms in bone marrow and drowning medium. J Forensic Sci 42: 286-290.

38. Pollanen MS (1998) Diatoms and homicide. Forensic Sci Int 91: 29-34.

39. Azparren JE, Vallejo G, Reyes E, Herranz A, Sancho M (1998) Study of the diagnostic value of strontium, chloride, haemoglobin and diatoms in immersion cases. Forensic Sci Int 91: 123-132.

40. Yange L, Hu C, Chengxing W, Xu W (1999) Development of Can for Destruction of Organic Material in use for Forensic Diatom Examination. For Sci Int101: 163-166.

41. Hürlimann J, Feer P, Elber F, Niederberger K, Dirnhofer R, et al. (2000) Diatom detection in the diagnosis of death by drowning. Int J Legal Med 114: 6-14.

42. Gruspier KL, Pollanen MS (2000) Limbs found in water: investigation using anthropological analysis and the diatom test. Forensic Sci Int 112: 1-9.

43. Bhatt JP, Ajay Jain, Bhaskar A, Pandit MK (2001) Pre-impoundment study of biotic communities of Kistobazar Nala in Purulia, West Bengal. Current Science $81: 10$

44. Kazutoshi AGO, Mihoko AGO, Mamoru OGATA (2004) The Distribution of Diatoms in Yoro The Yoronjima and Application of the Diatom Test for the Diagnosis of Death by Drowning in Open Sea Islands. Med J Kagoshima Univ 56: $25-29$

45. Pollanen MS, Cheung C Chiasson DA (1997) The diagnostic value of the diatom test for drowning, I. Utility: a retrospective analysis of 771 cases of drowning in Ontario, Canada. J Forensic Sci 42: 281-285

46. Timperman J (1969) Medico-legal problems in death by drowning. Its diagnosis by the diatom method. A study based on investigations carried out in Ghent over a period of 10 years. J Forensic Med 16: 45-75.

47. Ludes B, Coste M, Tracqui A, Mangin $P$ (1996) Continuous river monitoring of the diatoms in the diagnosis of drowning. J Forensic Sci 41: 425-428.

48. Peabody AJ (1978) Diatoms in forensic science. J Forensic Sci Soc 17: 81-87

49. Mueller B, Gorgs D (1949) Studien uber das Elindringen von corpiscularen Wasserbetandtielen aus den Lungenaveolen in des Kreislauf wahrend des Ertinkungsvorganges. Dtsch Z Gesamte Gerichtl Med 39: 25-71.

50. TIMPERMAN J (1962) The detection of diatoms in the marrow of the sternum as evidence of death by drowning. J Forensic Med 9: 134-136.

51. Fukui Y, Hata M, Takahashi S, Matsubara K (1980) A new method for detecting diatoms in human organs. Forensic Sci Int 16: 67-74.

52. Peabody AJ (1999) Forensic Science and Diatoms, In: Stoermer EF, Smol JP editors. The Diatoms: Applications for the Environmental and Earth Sciences. Cambridge: Cambridge University Press 413-418.

53. Siver FA, Lord WD, McCarthy DJ (1994) Forensic limnology: The use of fresh water community ecology to link suspects to an aquatic crime scene in southern New England. Journal of Forensic Sciences 39: 847-853

54. Cameron NG (2004) The use of diatom analysis in forensic geosciences, In: Pye K, Croft DJ, (eds). Forensic Geosciences: Principles, Techniques and Applications. London: Geological Society 232: 277-280. 